\title{
EL NUEVO MODELO RESIDENCIAL INDUCIDO POR LA CRISIS ECONÓMICA: EL CASO DE MADRID
}

\section{A NEW RESIDENTIAL MODEL INDUCED BY THE ECONOMIC CRISIS: THE MADRID CASE}

\author{
Jesús Leal \\ leal.je@gmail.com \\ Universidad Complutense de Madrid
}

\begin{abstract}
Resumen
Este artículo parte de la existencia de una tradición sociológica en el estudio de la vivienda desde perspectivas diferenciadas. En él se trata de ratificar la tesis de la existencia de un cambio de modelo en el sistema de vivienda, centrado especialmente en el caso de Madrid, que afecta a diversos factores tanto de los procesos de producción de vivienda como de los comportamientos residenciales. Este nuevo modelo supone un cambio drástico en las formas de tenencia, un cambio en la orientación de la movilidad residencial y el agravamiento de los problemas que supone compartir una vivienda con personas ajenas a la familia. El modelo que emerge de la crisis está influenciado por una serie de transformaciones demográficas, sociales y económicas que se han producido a lo largo del periodo estudiado.
\end{abstract}

Palabras Clave:sociología de la vivienda, política de vivienda, comportamiento residencial, sistema de provisión de vivienda, tenencia de vivienda

\begin{abstract}
This article departs from a sociological tradition in the study of housing from different perspectives. It seeks to confirm the thesis that there has been a change in the housing system model, especially in the case of Madrid, that affects various factors in both the processes of housing production and household residential practices. This new model suggests that there have been significant changes that include the duration of tenancy, the direction of residential mobility and a worsening of problems that arise from sharing a house with non- family members. The model that emerges indicates that the crisis had been influenced by a series of demographic transformations, social factors and economic factors that have occurred throughout the period studied.
\end{abstract}

Keywords: sociology of housing, housing policy, residential practice, housing provision, housing tenure 


\section{Introducción}

El acceso a una vivienda digna se ha convertido en gran parte de las sociedades avanzadas en un problema cíclico que suele resurgir cuando se dan cambios en la provisión o en la necesidad de ese bien (Cortés 1995). Cuando las formas de acceso se colapsan, se pueden generar problemas de gran envergadura que han llegado a inducir crisis como la experimentada recientemente que ha golpeado fuertemente a la economía y a la sociedad española a finales de la primera década del siglo XXI (Alguacil, y otros 2013).

El estudio de la vivienda ha acaparado la atención de los sociólogos y en concreto de aquellos mas dedicados a los temas urbanos desde hace más de un siglo. En estos estudios sobe la vivienda se presentan perspectivas diferentes que no suelen ser excluyentes sino complementarias.

Una primera perspectiva es la del estudio de la provisión de vivienda, considerada como un sistema en el que se integran diversas funciones: desde los urbanizadores o proveedores de suelo, hasta los comerciales que venden o alquilan una vivienda, pasando por constructores, promotores, técnicos y arquitectos. La diferente participación de esas funciones da origen a tipologías distintas que suelen estar relacionadas con las tipologías de residentes que acceden a ellas, Merton (1963) Desde otra perspectiva mas estructural, también se analiza la función de los agentes que intervienen en la producción, pero no tanto como elementos de un sistema sino como ejecutores de una lógica económica predeterminada Topalov (1970), Preteceille (1971), Castells y Godard (1974)

Como parte de esta perspectiva pero con unas connotaciones especiales podemos incluir también a los estudios sobre las diversas formas cómo el Estado actúa sobre esa producción o rehabilitación de la vivienda. La política de vivienda suscita un elevado número de investigaciones, ya que la intervención del Estado se hace estructural al tener que garantizar el acceso a un bien necesario que el mercado no puede cubrir en su totalidad.

Si nos centramos en la perspectiva de los usuarios, el objeto de estudio cambia, dejando de ser la vivienda para ser el residente el que centra la atención. También en esta perspectiva existen orientaciones diversas, desde la antropología como la que plantea Rappoport (1972), hasta aportaciones más recientes como la del sociólogo sueco J Kemeney (1992) para quien lo importante es el comportamiento espacial ligado a la función de habitar.

Las formas de relación del individuo con su vivienda, así como con las personas que componen el propio hogar o que comparten esos espacios circundantes, suponen para J Kemeney (1992) lo que denomina "prácticas residenciales o comportamientos residenciales", se trata de otro de los conceptos básicos que suelen ser considerados por la denominada Sociología de la Vivienda.

La cuestión que frecuentemente se presenta es cómo relacionar esa visión de la vivienda desde su producción con esta otra del comportamiento residencial de los hogares, esto es lo que abordan las investigaciones que tratan de ver las implicaciones de determinados tipos de viviendas o de determinadas formas de producción o rehabilitación sobre el comportamiento de los hogares en términos de tenencia, uso y cambio de residencia (Pittini et alt 2017).

En este artículo se trata de comprender el proceso de cambio en el sistema residencial que se está dando, concretado en el caso de la ciudad de Madrid de la que 
se dispone de la información básica para abordar la comprensión de ese sistema. Se trata en concreto de analizar cómo los cambios en el sistema de provisión de viviendas que se producen a partir de la crisis económica reciente explican un cambio a su vez en el comportamiento residencial de los hogares, ya sea en lo que respecta a su distribución territorial, a las formas de acceso, induciendo un aumento de la desigualdad social que se puede añadir a la que se da en términos de renta, de formación y de ocupación, manifestándose especialmente en diversas formas de segregación.

Se parte inicialmente de dos presupuestos importantes. El primero es que la provisión de vivienda es el resultado de una actuación de funciones diferenciadas sometidas a cambios que pueden llegar alterar de forma profunda el total de esa provisión y sus características en términos de localización, tamaño, tipología y precio a lo largo de un periodo determinado. Esa actividad constituye una parte importante de la economía de una región o país, no solo por lo que implica de formación de un patrimonio, con la construcción de nuevas viviendas, sino también por la movilización de elementos productivos que supone, desde el empleo que usa hasta la demanda de bienes secundarios, pasando por su financiación y su comercialización. Los cambios que han podido darse en la propia dinámica de su producción y su comercialización. Hay que tener en cuenta el impacto producido en España por la enorme producción residencial de comienzos del siglo XXI seguida de la drástica caída de la actividad productiva de vivienda, arrastrando consigo más de la mitad del incremento del desempleo generado.

En ese sentido se considera la hipótesis de que en la crisis económica experimentada a finales de la primera década de este siglo, hay una componente básica de cambio en el sistema de provisión de viviendas, llevando a incidir en los elementos que constituyen ese sistema, entre los que se encuentra especialmente el de la financiación, impactada por la morosidad de los hipotecados y la bancarrota de las empresas promotoras, algo planteado por autores como Naredo (2010) y Rodriguez (2009).

La segunda hipótesis es que ese cambio está relacionado con serias variaciones en los comportamientos de los hogares que parte de un cambio en las formas de convivencia, como se manifiesta en la reducción del tamaño del hogar, y de la composición demográfica de los demandantes de vivienda, suponiendo una variación en las formas de tenencia, con un incremento espectacular del alquiler, (lo que se desarrolla en otro artículo de este número). También se da un cambio de orientación en la movilidad residencial, con la vuelta a la ciudad consolidada, frente a la expansión del modelo precedente. Por otra parte se desarrollan las situaciones de precariedad residencial de los grupos más vulnerables. Las dificultades económicas sobrevenidas por la crisis se manifiestan también por un incremento de los desahucios, un retraso de la emancipación de los jóvenes, un incremento del hacinamiento y una reducción de las viviendas vacantes, especialmente de la categoría de viviendas vacías. Este cambio lleva a agravar la fractura social de las grandes ciudades españolas con un incremento de la segregación y con la generalización de procesos de gentrificación.

La rapidez y la intensidad de ese cambio del modelo residencial ha supuesto que las medidas políticas que se han introducido lleguen en ocasiones a ser contradictorias por su impacto sobre ese rápido cambio del modelo residencial, como ha sucedido con medidas tales como la desgravación fiscal o la reducción del tiempo de los contratos de alquiler. 


\section{El contexto}

Para confirmar la existencia de ese cambio de modelo residencial, se ha partido de una recogida de datos provenientes de diversas fuentes, la casi totalidad de ellas provenientes de organismos públicos, tales como los censos, los padrones y las encuestas nacionales. Pero también se recogen datos registrales como los que se basan en las informaciones provenientes del Ministerio de Fomento relativas a la producción de nuevas viviendas, o las de los registros judiciales que hacen referencia a los desahucios. Mas allá de estas fuentes de información hay que considerar que en España hay una escasez de datos sobre determinados aspectos de la condición residencial, en comparación con otros países europeos. Especialmente hay una dispersión y descoordinación de los datos provenientes de instituciones públicas, lo que aparece de forma extrema en temas como las estadísticas de precios de la vivienda, la distribución de los usos o de las dimensiones del parque residencial tal como plantea Palacios García (2008).

Este análisis de los datos secundarios no se considera cerrado sino que merece una extensión a partir de un desarrollo de entrevistas con los informadores privilegiados sobre el cambio acaecido así como la posibilidad de disponer de datos de encuestas que nos ayuden a consolidar las hipótesis que aquí se expresan

\subsection{El contexto sociodemográfico}

En el año 2016 la Comunidad de Madrid contaba con una población de 6,47 millones de habitantes de los que 3,17 pertenecían al Municipio de Madrid, y otros 3,15 al resto dela Región Urbana quedando otros 0,15 millones en las zonas rurales de la Comunidad. De los Habitantes del Municipio de Madrid, cerca de un tercio residian en el centro considerado como la "almendra" comprendida en el interior del espacio circundado por la autopista de circunvalación M-30 y compuesto en su casi totalidad por los 7 primeros distritos que podemos considerar como el centro de la capital y de toda la región.

Como cualquier espacio urbano la región está sometida a variaciones de las que en este caso hay que destacar tanto la dispersión en el territorio de las actividades productivas, más allá de sus límites, especialmente la de las oficinas, y de las comerciales los cuales suponen un fuerte impacto sobre la vida de los residentes en los barrios y municipios que componen la Región Metropolitana.

A lo largo de los últimos 30 años el crecimiento ha tenido ritmos diferenciados (Gráfico 1), muy marcados por una rápida expansión, seguido de una de las la crisis económicas más profundas de los últimos años, habiéndose dado un flujo migratorio sin precedentes con periodos de gran crecimiento demográfico y un ligero saldo migratorio negativo en algunos años recientes. El resultado supone un elevado flujo de extranjeros asentados en los años precedentes a la crisis que hacen que en su conjunto durante estos años se haya incrementado su población en más de 1,3 millones de habitantes, tal como se muestra en los Gráficos 1 y 2.

El estancamiento de la población durante la etapa posterior a la crisis afectó a todas las zonas, si bien destaca la pérdida de población que sufre el municipio de Madrid, de modo que dentro de este municipio sólo los distritos de Fuencarral y Hortaleza tienen en esos años un crecimiento positivo, debido a los desarrollos a los nuevos barrios de San Chinarro, las Tablas y Montecarmelo. 
Gráfico 1. Evolución del tamaño y la distribución de la Población de la Comunidad de Madrid (1998-2016)

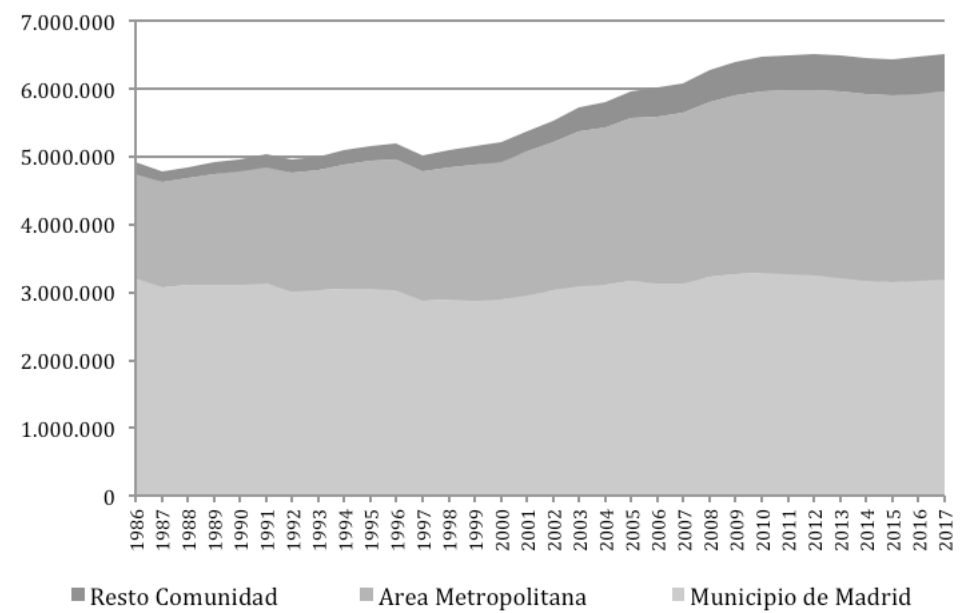

Fuente: Instituto de Estadística dela Comunidad de Madrid, Padrones municipales.

Para comprender el crecimiento demográfico experimentado por la región es importante tener en consideración el comportamiento de la población inmigrante y el atractivo que suponen las grandes ciudades españolas en la década de los 2000 , debido especialmente a la generación de empleo que en ellas se produjo. En 1998 la población nacida en el extranjero era inferior al $4 \%$ en la Comunidad de Madrid (Gráfico 2). Si analizamos el porcentaje de personas sin nacionalidad española era aún inferior: del 2,9\% del total de madrileños. Este crecimiento será positivo hasta el año 2010, año en que la población nacida en el extranjero alcanza su máxima proporción, llegando a suponer el $19,6 \%$ de la población total de la Comunidad, aunque decae ligeramente en los años inmediatamente posteriores.

Gráfico 2. Evolución dela proporción del total de personas nacidas en el extranjero residentes en la Comunidad de Madrid 1998-2016

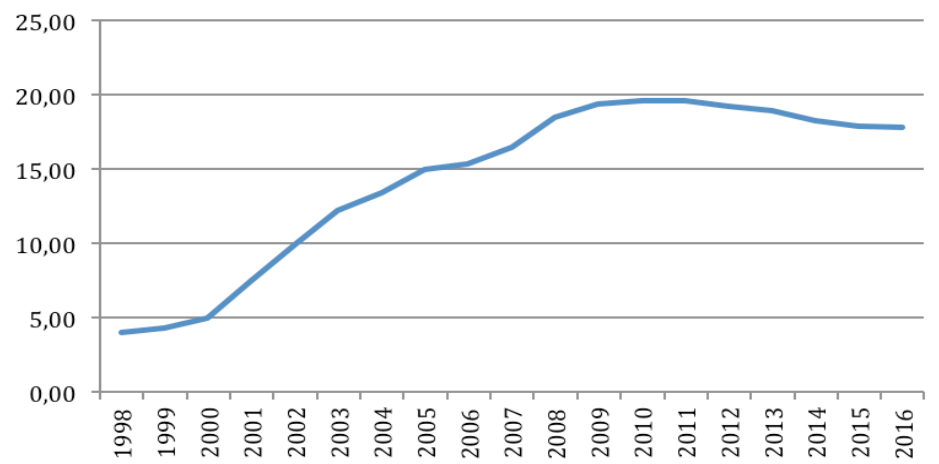

Fuente: Instituto de Estadística de la Comunidad de Madrid. Padrones municipales.

Esta población de origen extranjero muestra una presencia menor en las zonas que gozan de una renta per cápita más elevada, como son las del norte del Municipio de Madrid y los municipios situados al Norte y Noroeste de la capital, aunque en algunos distritos como Centro y Tetuán existe una proporción elevada de ellos. Los porcentajes 
más elevados respecto del total de la población se concentran en los barrios del sur y del este de la capital y de su corona metropolitana, coincidiendo con los lugares en los que hay mayor proporción de viviendas en mal estado y una mayor oferta de alquiler.

Más allá del crecimiento del conjunto de la población es importante tener en consideración las características de las misma en su distribución etaria, con un aumento de 3,5 años de edad media en el periodo 1998-2016, alcanzando los 41,2 años de media, 7,7 años más que la media de la población inmigrante que creció en 2,8 años y contribuyó poderosamente a rejuvenecer al conjunto de los madrileños, lo que explica la evolución de la distribución de edades (Gráfico 3).

Gráfico 3: distribución proporcional de los menores de 16 años y los mayores de 64 años en la Comunidad de Madrid.

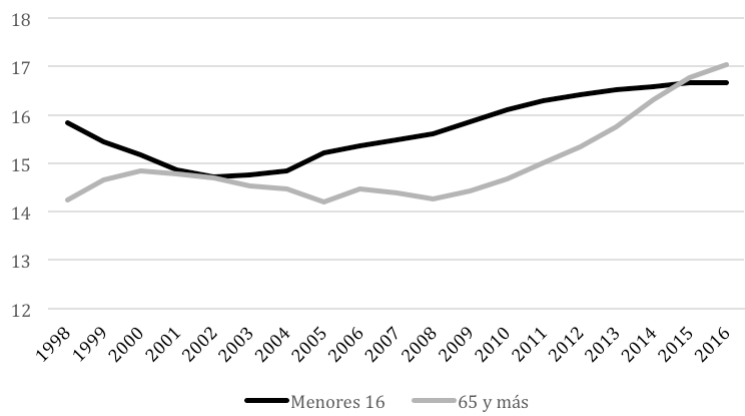

Fuente: Instituto de Estadística de la Comunidad de Madrid. Padrones municipales.

Este aumento de la edad media de la población madrileña se corresponde con dos factores importantes, el primero es el de un aumento de la esperanza de vida, alcanzando en la Comunidad de Madrid los 84,9 años en 2017, la más alta de todas las regiones europeas de su nivel territorial, tanto en hombres $(81,9)$ como en mujeres $(87,6)$ y con una ganancia de la proporción de mayores de 64 años que pasa del 14,5 del 2001 al $17,1 \%$ del total en 2016 . El segundo elemento que influye en el aumento de la edad media es el descenso de las cohortes más jóvenes, impulsado en parte por el retraso en la edad media a la maternidad. Esa población disminuye ligeramente su movilidad residencial en los últimos años, a pesar del incremento del régimen de alquiler entre los jóvenes emancipados a edades tardías, influida en esa disminución por el aumento de una población mayor más numerosa y con una proporción muy alta de viviendas en propiedad.

\section{El cambio en los hogares}

Frente a un crecimiento de la población en el periodo intercensal del 18,4\% los hogares se incrementan a un ritmo mucho mayor, creciendo un $28,8 \%$, debido a los cambios en las formas de convivencia, con una drástica reducción del tamaño de esos hogares, (Módenes y López Colas 2014). Así el número de hogares se alcanza un total de 2,41 millones para el conjunto de la Comunidad de Madrid en 2011 . En el periodo posterior el número de hogares continúa su aumento pero a ritmo menor alcanzando un total de 2,53 millones de hogares en 2015 , y cuyo número sobrepasa en más del doble a las 47349 viviendas nuevas que se construyen en esos 5 años (Ministerio de Fomento visados de fin de obra). Si se cuenta que una parte de esas nuevas viviendas vana reponer las demoliciones que se dan en ese periodo, se llega a que los hogares aumentaron en el periodo de la crisis evaluado, en más de tres 
veces que el parque de viviendas. La conclusión es que una parte de las viviendas anteriormente vacías o de segundas residencias, se incorporaron al mercado, si a ellas le añadimos las ocupadas por población transeúnte, como sería el caso de las viviendas turísticas, es comprensible que se haya dado una reducción de 120.000 viviendas no principales, tal como se deduce de los datos del Ministerio de Fomento, con un descenso del total de viviendas vacantes (secundarias más vacías) que pasan de representar el $15 \%$ al $10.6 \%$ del total de parque en esos 4 años.

El cambio en las formas de convivencia que fundamenta ese mayor aumento proporcional de los hogares que el incremento de la población, se fundamenta en el descenso del tamaño medio que pasa de 2,9 personas por hogar en 2001 a 2,5 en 2016. Los hogares unipersonales son los grandes protagonistas de ese cambio de tamaño, ya que aumentan su proporción sobre el total en 4,2 puntos alcanzando el $25,7 \%$ del total de los hogares, una proporción elevada pero todavía muy alejada de una presencia superior al $50 \%$ en ciudades como Berlín o Copenhague. La distribución espacial de de estos hogares de una sola persona es muy desigual, la mayor proporción de ellos se concentra en el municipio de Madrid, especialmente en la zona central ("La Almendra") en la que ya suponen más de un tercio del total (35\%), lo que quiere decir que en esta zona una de cada tres viviendas está habitada por una sola persona, que va a tener de media unos comportamientos residenciales diferenciados en algunos aspectos tales como un mayor uso de los servicios del barrio, especialmente los de cafeterías, restaurantes y bares, así como una tendencia a situarse en la proximidad de los grandes sistemas de transporte público.

Tan importante como el incremento de los hogares unipersonales es la disminución intercensal de los hogares de 6 y más personas, que disminuye su peso en casi la mitad para el periodo citado, pasando de 3,9\% al 2\% del total (Gráfico 4), a pesar del aumento de la población nacida en el extranjero que ocupa una buena parte de esos hogares numerosos y para los que la proporción entre ellos de hogares con dos o más familias $(5,1 \%)$ es muy superior a la de los nacidos en España $(3 \%)$. Esto nos habla de situaciones residenciales que pueden estar forzadas por las condiciones del mercado inmobiliario residencial y significar la posible existencia de un aumento del hacinamiento (Leal y Alguacil 2012).

Pero la existencia de hogares amplios no es únicamente privativo de inmigrantes y de hogares con escasos recursos, en las zonas de mayor renta media de la Comunidad, como Pozuelo de Alarcón, se llega a alcanzar valores de 3 personas por hogar, claro que se trata también de las zonas que tiene las viviendas de mayor superficie $(128,2 \mathrm{~m} 2)$ lo que suponen 43,5 m2/persona, 9,4 metros más que la media.

Gráfico 4. Porcentaje de hogares según tamaño. Comunidad de Madrid (1991-2016)

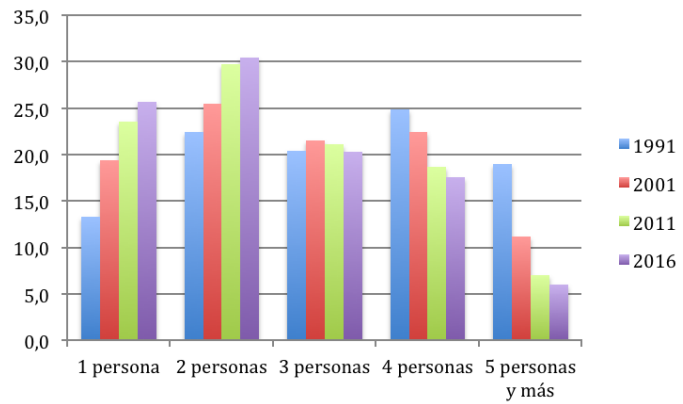

Fuente: Elaboración propia a partir de Censos y ECH. INE 


\section{La evolución del modelo residencial}

En Madrid el nuevo siglo despierta con un proceso de recuperación en la producción de viviendas que se había puesto en marcha un par de años antes, después de una crisis del mercado inmobiliario que se inició a lo largo del año 1992 y que podríamos calificar de corta y suave, en comparación con la que iba venir más tarde o con la que se había dado antes, a partir de la crisis del petróleo del final de la década de los setenta. Esa nueva crisis de los setenta había sido precedida por un incremento constante de los precios de las viviendas que tuvo un recorrido de 7 años desde 1985 hasta 1992, aunque ello no supuso un gran incremento de la edificación residencial metropolitana en Madrid. El descenso de los precios de la vivienda que la acompaña comienza por el centro de la capital, al igual que el experimentado en la crisis de los setenta, y se transmite como una ola que pierde intensidad en su expansión a la periferia urbana. El centro urbano pues es más sensible a las subidas de precio pero también lo es a las bajadas. Los precios de la periferia suelen ser menos volátiles pero con algunas excepciones marcadas por la estigmatización de su localización o por la distancia al centro, tal como sucedió con algunos barrios construidos al amparo de unas expectativas desmesuradas de expansión urbana, como en los casos de Seseña (urbanización Francisco Hernando) en la provincia de Toledo o en (Valdeluz) de la provincia de Guadalajara

Pero esa crisis de los noventa se puede decir que no afectó a la esencia de un modelo en el que las políticas de vivienda impulsaban de facto el acceso en régimen de propiedad, ya de por sí atrayente, por el notable descenso de los intereses de las hipotecas que experimentaron una transición a lo largo de la década de los noventa que pasó del $17 \%$ al $2 \%$ de interés y de un plazo de recuperación del capital que pasa de una media de 10 a 27 años En consecuencia el esfuerzo mensual de un hogar medio para acceder en propiedad descendió notablemente, a comienzos de siglo, a costa de su alargamiento temporal Este cambio fue propiciado por las exigencias del cambio de moneda, de la peseta al Euro que impulsó una política monetaria en la que la reducción de la inflación era uno de los objetivos prioritarios, este hecho junto con la estabilidad que suponía la inclusión en el Eurogrupo afianzó esa bajada de intereses y ese alargamiento temporal del reembolso de los créditos hipotecarios. Dos acontecimientos clave que condicionaron el fuerte crecimiento de la demanda de vivienda que se dio con la entrada del nuevo siglo. Pero los efectos de la crisis supusieron un descenso de los precios con su efecto sobre el esfuerzo, aunque las dificultades de acceder a una hipoteca no permitieron un aumento de la propiedad hasta años recientes (Gráfico 5) en los que remonta el precio y sube el esfuerzo requerido para la adquisición de una vivienda, tal como plantean gran parte de autores: Alguacil, A.et alt (2013,) Vinuesa (2013) J. Pareja Eastaway y Sanchez Martínez (2011), Naredo (2010)

\section{Grafico 5 Evolución del esfuerzo para acceder a una vivienda media en Madrid ( $n^{\circ}$ de años de salario}

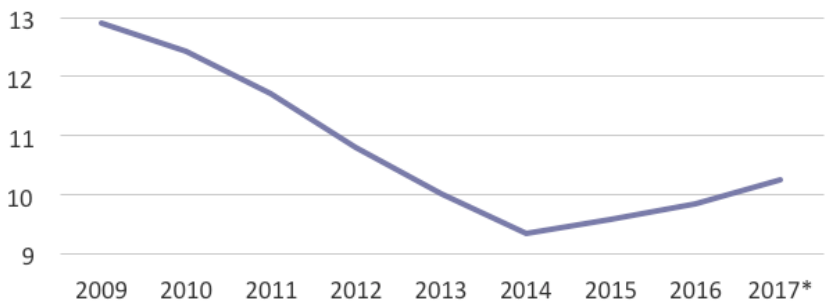

Fuente: Anuario estadístico de la Comunidad de Madrid y elaboración propia. 
A pesar del elevado crecimiento económico experimentado en Madrid en la primera década de los años 2000, las desigualdades territoriales referidas a la distribución de las rentas medias zonales per cápita sufren un incremento (Grafico 6), tal como sucede en gran parte de las capitales europeas durante ese periodo (Leal y Sorando 2017). Este aumento de las desigualdades supone unmayor distanciamiento del centro con respecto a las periferias y del Norte de la Región con respecto al Sur. Una brecha que no ha hecho más que aumentar a lo largo del último medio siglo.

\section{Gráfico 6. Evolución de la renta per cápita en las zonas de la Región urbana de Madrid}

(2002-2014)

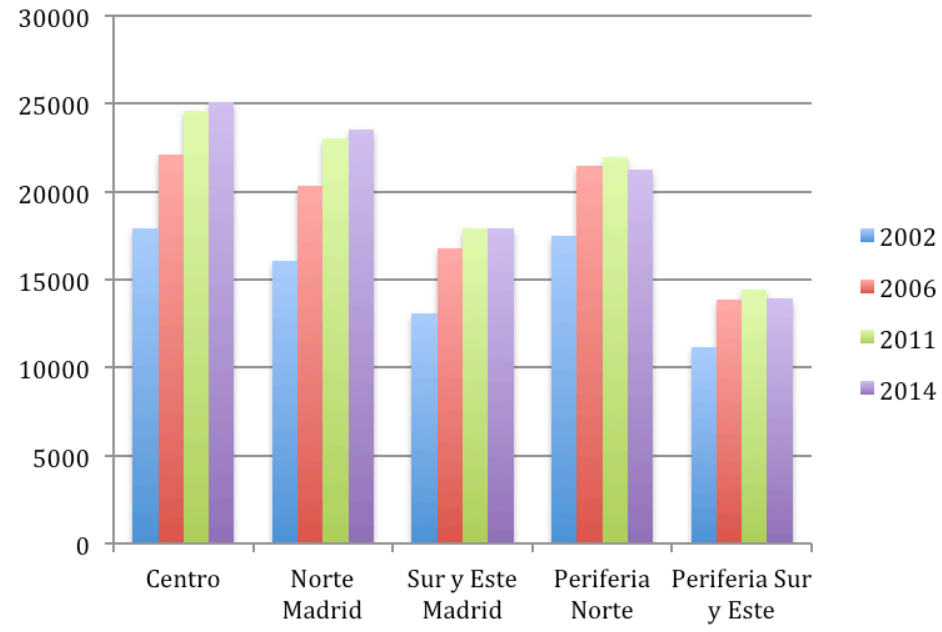

Fuente: Anuario estadístico de la Comunidad de Madrid, renta per cápita municipal.

Este aumento de la desigualdad económica viene acompañado de un incremento de la segregación, social medida a partir de las ocupaciones, hasta alcanzar unas posiciones extremas en la comparación con otras capitales europeas (Tammaru, Van Ham, Marcińczak y S. Musterd 2017). En ese proceso de desigualdad los mercados de vivienda jugaron un papel importante, de forma que también se incrementaron las diferencias de precio del metro cuadrado de las viviendas en relación con la localización, lo que supone de hecho un aumento de las desigualdades del patrimonio de los madrileños, algo que tiene una gran relevancia en la constitución de las desigualdades económicas, como sostiene Picketty (2014).

A la mejora experimentada, en el conjunto del país, en el acceso a los préstamos hipotecarios, se le añadió el mantenimiento de la desgravación fiscal en la adquisición de la primera vivienda que ya venía dándose con anterioridad en España. Las medidas de fomento del acceso a la propiedad, como la desgravación por inversión en primera vivienda, suponían una proporción de más del $70 \%$ de las ayudas estatales a la vivienda (Rodríguez 2009, Leal 2017) a pesar de su carácter regresivo, ya que eran las rentas más altas las más beneficiadas (Sánchez Martínez 2002). El mantenimiento de esta medida contribuyó a incentivar la demanda en un momento en el que su gran volumen era inquietante por las dificultades que tenía su normalización, lo que aconsejaba reducir los incentivos de acceso a la propiedad.

La eliminación de la desgravación fiscal o su sustitución en la misma cuantía en ayudas directas fue una demanda de los responsables de la política de vivienda, conscientes esos efectos sobre la subida de los precios. En efecto, en el establecimiento 
de los precios de las viviendas, los promotores contaban con ese aumento de capacidad para el pago de las hipotecas por los adquirentes. Pero la realidad era que el superávit del presupuesto estatal no aconsejaba incrementar la carga fiscal que hubiera supuesto la supresión de esta ayuda, con lo que en realidad se manifestaba que el objetivo de esa desgravación fiscal por adquisición de vivienda iba más allá de facilitar el acceso a la vivienda, buscando con ella principalmente un instrumento para reducir la carga fiscal de los hogares, especialmente los de rentas medias y altas. De nuevo se manifiesta con ello el hecho de que las medidas de actuación sobre la vivienda tienen objetivos que van más allá de facilitar el acceso a la vivienda de los hogares con menos recursos.

En estas condiciones, el aumento de los hogares propiciado por el fuerte flujo inmigratorio llevó a incrementar aún más la demanda de vivienda en una situación de desequilibrio que influyó poderosamente sobre los precios que experimentaron una escalada considerable, como no se había dado en los procesos de crecimiento anteriores.

\section{La provisión de viviendas}

El hecho del aumento de la producción que llegó a alcanzar en el periodo 2001-7 las 656,7 miles de viviendas visadas anualmente en España y las 62,5 miles en el caso de Madrid, junto con la constante elevación de los precios de las mismas, fue lo que constituyó la denominada burbuja inmobiliaria residencial. Esa situación empieza a retroceder a mediados del año 2007, debido a una caída de las expectativas de revalorización, junto con una mayor estabilidad en el saldo migratorio y un mayor control de los préstamos por las entidades crediticias, arrastrando en los 9 años siguientes una caída de las viviendas iniciadas (visados) del 87\% en España y del 79\% en Madrid, respecto a los primero años del siglo XXI.

El rápido crecimiento de la población y el enorme aumento de la producción de viviendas no fue un fenómeno generalizable al resto de los países europeos, solamente el caso de Irlanda podría asemejarse algo al experimentado en España y más en concreto en Madrid.

La caída comienza en España un año antes del hundimiento de la empresa financiera Lehman Brothers, el 15 de Septiembre de 2008 en Estados Unido. La quiebra venia dada por el hundimiento de los fondos que integraban cierto número de hipotecas de escaso valor ("subprime") por la duda de su reembolso junto con otros valores más seguros, lo que suponía un ocultamiento de su contenido y por tanto de su riesgo real. Esta crisis global vino provocada por las intenciones de ampliar el mercado hipotecario a base de hacer propietarios a hogares de escasos recursos que ante los cambios en el mercado de trabajo no pudieron pagar sus hipotecas.

En el caso español, aunque esos fondos tuvieron poco impacto, en esencia se adoleció de las misas razones. El sistema inmobiliario español se hunde en poco tiempo lastrado por una enorme subida de los precios de las viviendas, por una saturación del mercado con el consiguiente aumento de la morosidad en el pago de las hipotecas contraídas, y la súbita caída de la demanda Vinuesa, j. (2013). Esta caída tardó un tiempo en manifestarse en el número de viviendas terminadas ya que había que terminar las operaciones en marcha, pues una paralización de las mismas hubiera incrementado las perdidas de las empresas que las promovían. Por otra parte una serie de promotoras fueron incapaces de vender las viviendas recién construidas y 
no pudiendo afrontar posteriormente la restitución de los préstamos contraídos, cuyo monto global en 2013 alcanzaba los 160 mil millones de Euros. En esa situación una parte importante del patrimonio de viviendas invendidas y de solares pasó a las entidades crediticias.

La crisis ha implicado un cambio notable en el sistema financiero con la desaparición de un gran número de Cajas de Ahorro, la agrupación de otras y su generalizada reconversión en bancos. La consecuencia fue en primer lugar una restricción drástica de la concesión de préstamos hipotecarios y el hundimiento de las expectativas de demanda tanto de una parte importante de los solares como de las viviendas recién construidas, lo que trajo una paralización de la construcción residencial que afectó sobre todo a las promotoras privadas y públicas y algo menos a las cooperativas que disponían ya de un suelo lo que explica una mayor proporción de esa forma de promoción respecto al total en los años posteriores a la crisis.

\section{La tenencia, el tamaño, la dispersión.}

La caída del mercado inmobiliario residencial (Gráfico 7) arrastró consigo algunas de las características básicas del modelo precedente, aunque se puede decir que ya existía anteriormente un embrión de esos cambios que se iban a desarrollar en los años siguientes.

El gran volumen del invendido en toda España, cifrado al comienzo de la crisis en 600.000 viviendas, y el efecto sobre la capacidad de concesión de préstamos de los bancos, trajo consigo la creación por parte del Estado de una sociedad que absorbiera una parte considerable de esas viviendas para aliviar el peso que tenían sobre los activos de los bancos. Se trataba de la SAREB "un banco malo" que adquiría viviendas de las entidades bancarias para después venderlas, a particulares o a fondos de inversión (Ayuso y Del Rio 2013).

Gráfico 7. Evolución del porcentaje de viviendas certificadas fin de obra en España, la Comunidad de Madrid sobre el total del parque precedente (2001-2016)

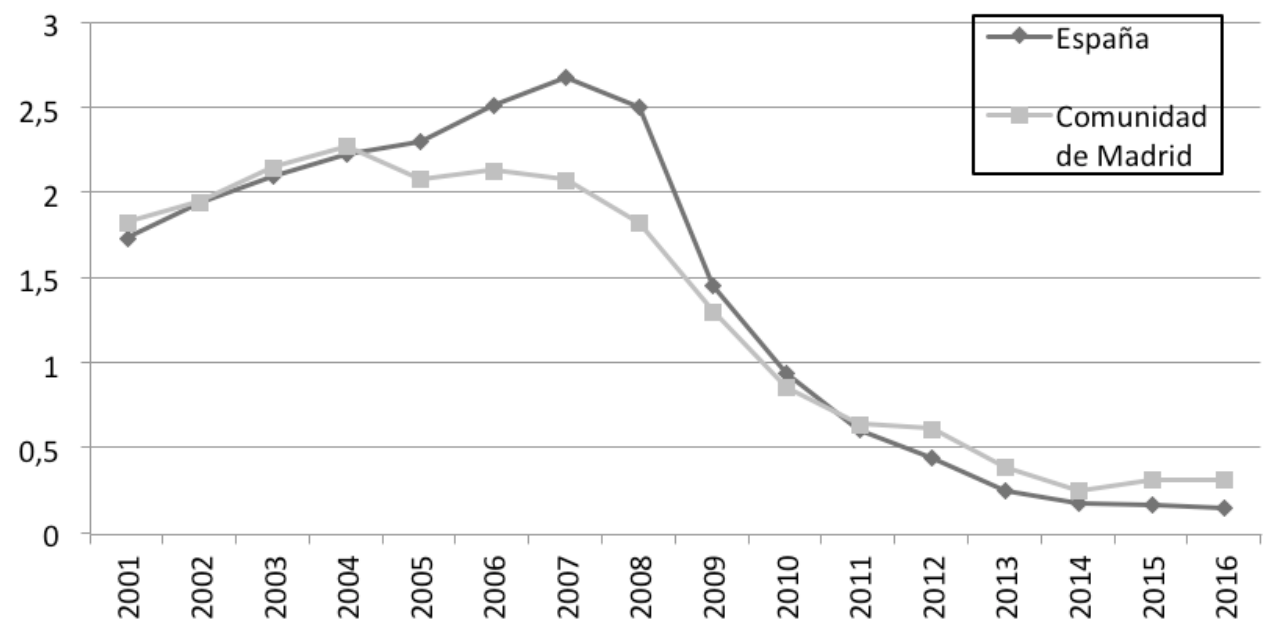

Fuente: Elaboración propia. Datos de España y la Comunidad se han utilizado los proporcionados por el Ministerio de Fomento. 
Socialmente la crisis que se derivó tuvo unas consecuencias muy duras. El desempleo llegó a superar en España los 6 millones, lo que suponía el $26 \%$ de la población activa, con lo que una gran cantidad de adquirentes de vivienda, que estaban pagando sus hipotecas, se vieron de pronto sin recursos para poder continuar con sus pagos. El resultado fue un gran desarrollo de desahucios por impago de las hipotecas aunque su composición ha cambiado, con un descenso de los lanzamientos por impago hipotecario y el aumento de los que se deben a la aplicación de la ley de arrendamientos urbanos, en los que se da un crecimiento reciente (Consejo General del Poder Judicial) llegado a provocar una serie de movimientos sociales entre los que destacó la PAHA (Plataforma de Afectados por las Hipotecas) y supuso uno de los elementos de descontento que están en la base de las manifestaciones del 15 de Mayo de 2011 en Madrid que tuvo una gran repercusión en todo el país (Trabada 2015, Cano, y Etxezarreta 2014).

Se trata de una crisis que diez años después de su explosión, todavía no se ha superado totalmente, debido a las secuelas que dejó, tanto monetarias, con una elevada deuda pública y también privada, como el hundimiento de miles de empresas que se vieron fuertemente afectadas por el retroceso de la demanda y lanzó a muchos hogares jóvenes que antes accedían en propiedad a alquilar todo tipo de viviendas e incluso a compartir su uso para poder alojarse (Echaves 2015).

Mucha gente perdió su vivienda y sus ahorros, una parte importante eran inmigrantes extranjeros que habían venido a España en busca de unas mejores condiciones salariales, algunos de ellos aprovecharon el programa del Estado para volver a sus países de forma que nos encontramos entre 2013-2015 saldos migratorios negativos en la Comunidad de Madrid, así como una reducción de la proporción de inmigrantes de países de América Latina, especialmente los de El Ecuador que habían llegado a ser el grupo más elevado de inmigrantes en los años del gran desarrollo.

El descenso en la producción supuso la puesta en el mercado de un número creciente de viviendas secundarias y vacías que pasan del 20,7\% en 2001 al 14,7 en 2011 y al $10,6 \%$ en 2015 , de las que $5,6 \%$ pertenece a las vacías y el $5 \%$ a las secundarias. Ese fuerte descenso de las viviendas vacantes tiene su contrapartida en el crecimiento de los alquileres, que pasan de representar en la Comunidad de Madrid el $15,4 \%$ de las viviendas ocupadas en 2004 al 22,9\% en 2015, y en su encarecimiento, una vez saturada la posibilidad de ampliar la oferta. A medida que desciende esa proporción de vacantes se hace más difícil la puesta en el mercado de alquiler de esas viviendas, hasta llegar a una proporción estructural de viviendas vacías necesaria para que funcione el mercado de alquiler y venta, ya que la proporción de vacías que quedan forman en gran parte el fondo que permite la rotación de adquisiciones y alquileres, debido al tiempo que transcurre desde que se vacía una vivienda hasta que se vuelve a ocupar por los siguientes propietarios o inquilinos.

Los demandantes de vivienda nueva en propiedad se concentran entre los hogares de rentas más altas. Esto se deduce del hecho de que las pocas viviendas que se construyeron durante este periodo posterior a la crisis incrementan el tamaño medio que venía dándose, tanto en las colectivas como en las unifamiliares (Gráfico 8). 
Gráfico 8. Evolución del tamaño medio (metros cuadrados) de las viviendas construidas en Madrid, por tipos.

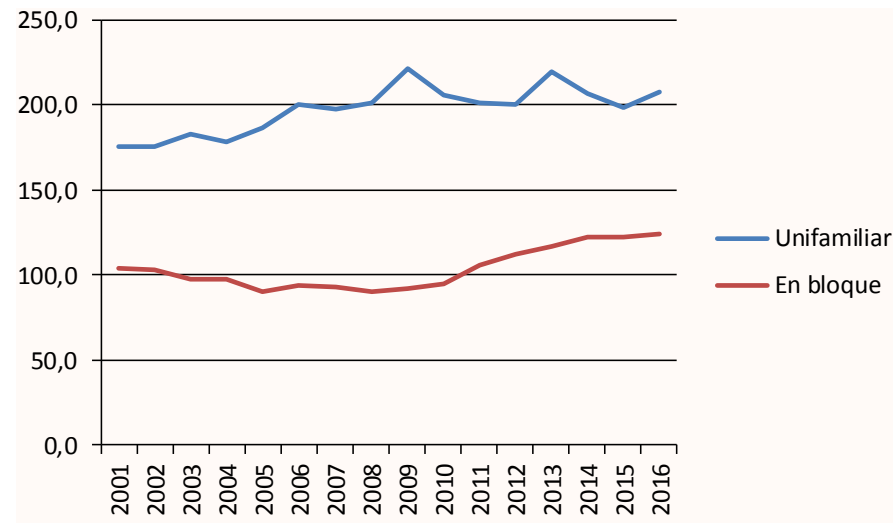

Fuente: Ministerio de Fomento: Visados de obra nueva

\section{El nuevo modelo emergente.}

Ante los efectos que suponía la crisis del sector inmobiliario residencial, se dieron dos intervenciones públicas que condicionaron fuertemente los cambios que caracterizan el nuevo modelo. La primera es la supresión de la desgravación fiscal por adquisición de nueva vivienda de uso permanente, algo que venía reclamándose desde hacía tiempo por el carácter regresivo de la misma.

La segunda medida política importante que afecta fuertemente a esa provisión de viviendas es la nueva ley estatal de arrendamientos urbanos de 2013 en la que destaca sobre todo la reducción de la duración mínima exigible a los contratos normalizados que pasa de 5 a 3 años, así como la agilización de los procedimientos de desahucio cuando incurren ciertas circunstancias, como es el impago del alquiler. El problema que supuso esta ley, es que consideraba que para incrementar la provisión de viviendas en alquiler había que aumentar las garantías de los propietarios arrendadores frente a la estabilidad y la seguridad de los inquilinos, haciendo más insegura su continuidad en la vivienda alquilada en el caso de que se dé un incremento fuerte de los precios de alquiler, ya que la garantía de un crecimiento sujeto al aumento del IPC quedaba limitada en dos años menos.A esta medida le acompañaron otras que reforzaban las garantías de los arrendadores reforzando sus garantías, con la intención de que esto supusiera una puesta en el mercado de las viviendas vacías y secundarias, como así fue.

\section{Las consecuencias del nuevo modelo}

La nueva orientación del modelo residencial español supone en su conjunto un agravamiento de las condiciones residenciales, tal como se planteaba al comienzo. El descenso en la producción vino acompañado de un incremento de las transacciones de viviendas de segunda mano frente a las viviendas nuevas (Gráfico 9), lo que se manifiesta también por los cambios en la movilidad residencial y en concreto por los procesos de gentrificación de las zonas centrales protagonizado por las clases medias provenientes de la periferia. 
Gráfico 9. Evolución del número de transacciones de viviendas en la Comunidad de Madrid (2004-16)

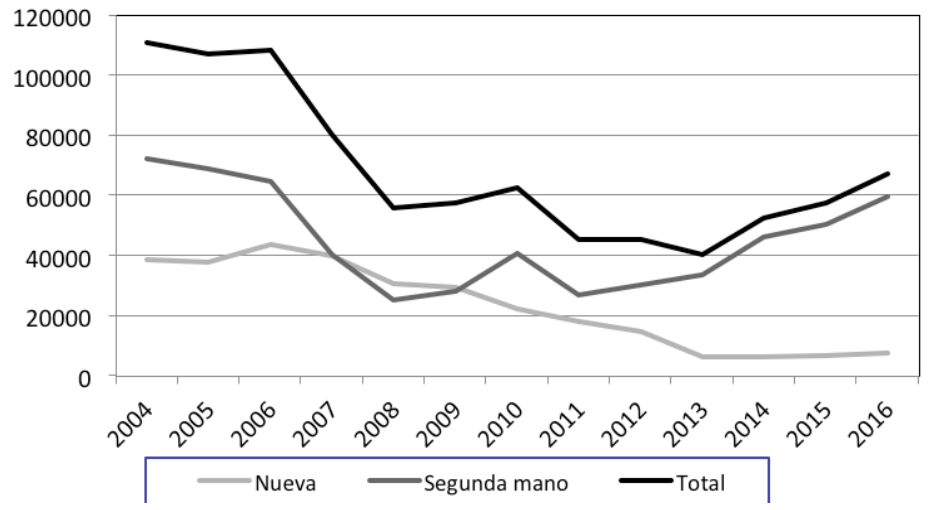

Fuente: Ministerio de Fomento

Como consecuencia de ese cambio en la provisión de viviendas y de la muy escasa producción de nuevas viviendas en los años posteriores a la crisis, se produce un desequilibrio en el mercado, lo que explica también la reducción de las viviendas vacías y secundarias que se manifiesta por el incremento de los hogares por encima del incremento del parque de viviendas. Este fenómeno que también se da en Barcelona, supone que se ha saturado la ocupación del parque de viviendas disponible, con el incremento consiguiente de sus precios, primero los del alquiler y posteriormente los de venta.

El otro tema en el que se manifiesta ese cambio de modelo ha sido en la disminución de las viviendas vacantes. Si ya existen problemas sobre la información de las viviendas ocupadas, con las viviendas vacantes que agrupan las vacías y las secundarias, los problemas de información son aún mayores. Todo lleva a plantear que las estadísticas oficiales sobrevaloraban el número de viviendas vacías que a veces resulta difícil diferenciarlas de las secundarias. La comparación entre los censos de 2001 y 2011 muestra una disminución de las vacantes, aunque dicha diferencia podría atribuirse en parte a las metodologías distintas de ambos censos. Pero la confrontación de los datos sobre la variación de hogares nos lleva a reafirmar las evaluaciones presentadas por el Ministerio de Fomento que suponen una gran reducción para estas viviendas, tal como se ha expresado anteriormente, algo significativo que parece que ha pasado desapercibido.

Tras la caída de la demanda en 2007 se acumularon una cantidad notable de viviendas vacías entre las recién construidas, lo que fue recogido en los medios de comunicación, por la paradoja que suponía esta situación en relación con la existencia de unas necesidades insatisfechas, en parte provenientes de los desahucios. Pero todo lleva a que las medidas de impulso del alquiler se basaba en parte en una puesta en el mercado de una parte del parque de vacías y secundarias, especialmente las situadas en las zonas urbanas consolidadas. En realidad a lo largo de los últimos años se ha dado un descenso pronunciado en la proporción de estas viviendas vacías en Madrid que en 2017 suponen una proporción del 5,6\% del parque total de viviendas, menos de la mitad de la proporción expresada en el censo de 2001 y un $5 \%$ de las viviendas secundarias. Es decir que se está llegando a una proporción estructural de las vacías y a una proporción de las secundarias que es una de las más bajas de las comunidades autónomas españolas. 
Estos cambios en el sistema de provisión de viviendas interactúan con una serie de cambios en los comportamientos residenciales que son parte integrante del nuevo modelo. No se puede decir que haya una secuencia causal entre los dos porque los cambios en los comportamientos residenciales no provienen únicamente de esa diferente forma de provisión de viviendas sino que tienen que ver también con otras variables tales como la dinámica de la población y de los hogares, la distribución de la renta, e incluso elementos culturales e ideológicos, como ha sido la atracción del centro para las clases medias o la propia consideración de pertenencia o identidad con un barrio o una zona determinada.La determinación de los efectos requeriría acotar algunos tipos de comportamiento y hacer un análisis detallado para ver con cierta aproximación el impacto de cada uno de los elementos que la condicionan, lo que no es el propósito de este artículo, sino más bien dar una visión global de los cambios que se han producido para posteriormente en otras investigaciones proceder a estos análisis más detallados.

El primer cambio es sin duda el de la forma de tenencia, que supone una ruptura con los procesos de aumento continuado de la tenencia en propiedad que venía dándose de forma ininterrumpida a lo largo de más de medio siglo. La tenencia de vivienda en alquiler pasa del 18,3 e 2004 al 24,5\% del parque de viviendas ocupadas (Gráfico 10 ), en un proceso creciente que al no poder ser respondido por la provisión de este tipo de viviendas provoca una considerable subida de precio del alquiler medio que supone $35 \%$ entre 2014 y 2016 frente a un 8,5\% del precio de venta. Esta subida supone que a largo plazo, en las condiciones actuales sea más rentable comprar que alquilar, porque las cuotas hipotecarias, una vez invertido el $20 \%$ inicial, son mas bajas que los alquileres para una vivienda del mismo tipo.

Paradojicamente este cambio se da en un momento en el que gran parte de los países europeos incrementan su proporción de residentes propietarios. Pero este es un tema que se desarrolla en otro de los artículos del presente número de esta revista, por lo que no vamos a profundizar aquí en su análisis, aunque hay que considerar que esta es una de las principales características del cambio que experimenta el modelo.

Gráfico 10. Evolución del alquiler en España y en la Comunidad Autónoma de Madrid en porcentaje (2004-2016)

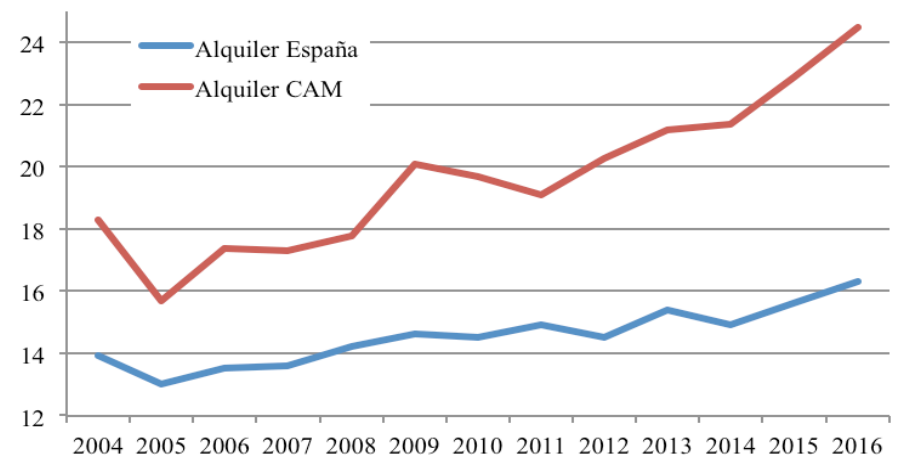

Fuente: Elaboración propia a partir de la Encuesta de Condiciones de Vida

El segundo aspecto que es necesario tener en cuenta tiene que ver con el nivel alto de desahucios que se produce, pasando recientemente de una mayoría de desahucios por impago de hipotecas a otra de mayoria de desahucios de inquilinos(Trabada 
2015). En efecto las medidas tomadas para evitar desahucios de hipotecados por parte del Gobierno y de las entidades crediticias, junto con la elevación de los precios de la vivienda que pueden hacer más conveniente su venta ante la imposibilidad de un impago de las hipotecas contraidas, suponen una reducciónde este tipo de desahucios. Pero frente a ese efecto, en el extremo contrario la elevación de los alquileres producida en parte por una escasez de los mismos, junto con la aplicación de la ley de arrendamientos de 2013 ha supuesto un incremento de los hogares que no pueden pagar los alquileres que les reclaman los propietarios. En este aumento de precio, en el caso de las zonas centrales influye las posibilidades más lucrativas del cambio de uso para viviendas turísticas. El problema es que no existen instrumentos públicos adecuados para ofrecer alternativas viables a estos deshaucios, teniendo en cuenta la reducción del parque público de viviendas sociales debido a la venta de una proporción no desdeñable (alrededor de 6000 viviendas), a fondos especulativos que tratarán de ponerlas en el mercado a un precio de alquiler o venta bastante superior al de su adquisición.

El tercero es la escasa producción de nuevas viviendas tras 2008 , que ha contribuido a que las pocas adquisiciones que se producen se dirijan con preferencia hacia las viviendas usadas que aumentan su peso en esas transacciones frente al de viviendas de nueva construcción que llegaron a representar cerca de la mitad del total en la primera parte del siglo.

A la vez se da un cambio en la dirección de la movilidad residencial, con la reducción de los movimientos hacia la extrema periferia a la par que aumentan las mudanzas dentro del propio barrio o en lugares cercanos a la residencia previa. De forma que el Municipio de Madrid que tenía un saldo negativo en ese movimiento de hogares, vuelve a situaciones positivas, aunque de forma diferencial según los distritos. Los procesos de gentrificación, con la preferencia por localizaciones centrales de la Región Metropolitana han supuesto también una presión sobre los precios y un desplazamiento de los que no pueden afrontarlos.

En el cuarto lugar, como consecuencia del fuerte descenso de la producción de nuevas viviendas y de la dificultad económica sufrida por la mayor parte de los hogares de la Comunidad, se da un cambio en los procesos de movilidad residencial, caracterizado por un movimiento centrípeto, hacia el centro del Municipio compuesto por los 7 primeros distritos y por un mantenimiento de los traslados de corta distancia hacia en el mismo distrito o los adyacentes con lo que se frena claramente el anterior proceso de dispersión periférica de los hogares. Esta tendencia tiene que ver con la preferencia de un acceso en alquiler por parte de los jóvenes que son las personas más móviles en el conjunto de los grupos de edad.

Las dificultades para la movilidad residencial de los que viven en viviendas de su propiedad, suponen una mayor proporción de desadaptación física de las viviendas a las necesidades, lo que se manifiesta de forma más intensa entre las personas mayores que en ocasiones se ven a obligados a vivir en viviendas demasiado grandes, sin aislamiento, con costes elevados de mantenimiento, con problemas de barreras y con carencia de ascensores.

La mayor atracción de los lugares centrales, se expresa en los procesos de gentrificación y en la elevación del precio de la vivienda en estos lugares de la ciudad, debido al aumento de la demanda de los mismos. La explicación de esa atracción del centro hay que encontrarla también en el incremento de los hogares constituidos por una o dos personas únicamente, descrito anteriormente. Estos hogares prefieren residir en localizaciones centrales, debido a la proximidad de servicios y al disfrute 
de unas redes de transporte público más tupida que les permite desplazarse con más facilidad. La inversión en la mejora urbanística de estos lugares centrales también ha experimentado un papel importante en esa atracción. Ese cambio en el crecimiento periférico se manifiesta también en la reducción de la proporción de viviendas unifamiliares construidas que se localizaban de forma preferente en los bordes de la Región y que pasan de representar el 19,3\% de todas las viviendas en edificios residenciales durante los primeros ocho años del presente siglo a el $11,5 \%$ en los siguientes ocho años entre 2009 y 2016.

El sexto elemento es el aumento de las situaciones de hacinamiento. Aunque es difícil de probar con los datos de los que se dispone los cuales muestran en cualquier caso que esta situación afecta principalmente a los inmigrntes que no tienen otra alterativa residencial que la de compartir su vivienda con otros piso con otros. El problema se agudiza cuando se trata de nucleso familiares sin relaciones de parenesco, obligadas a compartir un piso, generalmente de tamaño reducido.

Estos cambios contribuyen a incrementar los índices de segregación y la desigualdad patrimonial existente entre los madrileños, en la medida de una repercusión zonal diferencial de los precios que beneficia a los propietarios de los lugares centrales y a los más valorados socialmente. El incremento de la segregación que arroja la comparación de los censosde 2001y 2011(Leal y Sorando 2016), da idea de ese proceso en el cual hay que tener en cuenta que las diferencias en la edad se adjuntan a las diferencias sociales, la dificultad de alojarse de las nuevas generaciones se hace más compleja de la que tuvieron sus padres y eso lleva a un asentamiento diferencial dentro de las área construidas.

La séptima consecuencia considerada es el cambio en la tipologia de las nuevas viviendas en la que la búsqueda de una mayor seguridad lleva a desarrollar condominios cerrados con vigilantes, rejas y sistemas de control e identificación junto con un vaciamiento del espacio público, lo que a su vez contribuye a incrementar la sensación de inseguridad. La búsqueda de una mayor seguridad es una variable que irrumpe en el mercado residencial, probablemente para quedarse, algo propio de una sociedad en la que decaen las relaciones de proximidad a la vez que la confianza en la solidaridad local.

\section{Conclusión}

Tal como se planteaba, el cambio en el sistema residencial con la reducción de la provisión de viviendas y la variación en el comportamiento de los hogaresl suponen otra vez el aumento de la exclusion residencial, el empeoramiento de las condiciones de alojamiento asi como una mayor dificultad para poder disponer de una vivienda, en especial por parte de aquellos hogares jóvenes que no tienen un patrimonio para pagar la entrada de un piso o la abultada garantia y las cuotas mensuales de algunos alquileres. El nuevo modelo que se ha generado genera una mayor desigualdad residencial, no solo en la distribución territorial sino también en el aumento de los que no pueden difrutar de una vivienda digna.

Los elevados precios de compra y alquiler fomentan un cambio en la orientación de la movilidad, en la que un cambio de vivienda en propiedad puede suponer elevados costes en gastos e impuestos que en cualquier caso superan el $10 \%$ del coste de la nueva vivienda. 
Esa situación se ha enfrentado con una reducción de la inversión pública en vivienda que constituye la hermana más castigada de los elementos que constituyen en Estado de Bienestar. Los desahucios, las dificultades de tener un hogar familiar exclusivo para muchos inmigrantes y el retraso de los jóvenes en los proyectos de formar un hogar, se enfrentan con exige un cambio en las políticas de vivienda, especialmente en lo que se refiere a la la escasez de viviendas sociales en alquiler a precios que puedan afrontar. Su realización supondría una mayor implicación pública a todos los niveles administrativos, desde el Estado central hasa el poder local, pasando por las autonomías.

Hay que tener en cuenta que el tipo de política residual en el que la intervención pública actúa sobre el mercado, para garantizar el acceso a la vivenda de los hogares sin capacidad para conseguirlo en el mercado libre, es algo común a los países liberales, dentro de los cuales se consideraría a España. Este es un tema pendiente que exigiría una inversión continuada a lo largo de una serie de años para poder acercarse a la situación de otros países. En ese aspecto Madrid parte de una posición desventajosa porque una parte importante del parque de vivienda social de titularidad pública, tanto municipal como autonómica, se ha mercantilizado, habiendo sido vendido a fondos de inversión durante la crisis, lo que lleva a que el camino que tiene que recorrer para conseguir ese parque de vivienda social es más largo que el de otras comunidades autónomas.

Por otra parte hay que implicar al conjunto de la sociedad en el impulso de esas viviendas sociales que no tienen por qué ser públicas en su titularidad o en su gestión. La creación de patronatos de vivienda propiedad de una fundación o de alguna empresa grande, o el desarrollo de entiddes no gubernamentales que las posean o que las gestionen, podria ser también una solución en España como lo es en gran parte de los paises europeos.

De cualquier manera ese parque de vivienda social es un requisito imprescindible para poder alcanzar la implantación de un verdadero derecho positivo de acceso a una vivienda digna, haciendo efectivo el artículo 47 de la Constitución Española que expresa ese derecho. 


\section{Referencias}

Alguacil, A. y otros (2013).La vivienda en España en el siglo XXI. Madrid: Fundación Foessa.

Ayuso, J. y del Rio, A. (2013). "La resolución de activos bancarios a través de "bancos malos". Revista de Estabilidad Financiera, Banco de España, $\mathrm{n}^{\circ} 23$.

Cano, G. y Etxezarreta. A. (2014). "La crisis de los desahucios en España: respuestas institucionales y ciudadanas". Revista de Economía Crítica, n¹7, primer semestre

Castells M. y Godard, F. (1974). Monopolville analyse des rapports entre l'entreprise, l'État et l'urbain à partir d'une enquête sur la croissance industrielle et urbaine de la région de Dunkerque, Paris/La Haye, Mouton

Cortés, L. (1995).La cuestión residencial. Bases para una sociología del habitar. Madrid: Editorial Fundamentos.

Echaves, A. (2015). "Pautas emancipatorias de los jóvenes españoles y acceso a la vivienda en el actual contexto de crisis". Documentación Social. Nº 176. Pp.:15-36.

Kemeney, J. (1992).Housing and social theory. Londres: Routeledge.

Leal, J. y Aguacil, A. (2012). "Vivienda e inmigración: las condiciones y el comportamiento residencial de los inmigrantes en España”. En Aja, E.; Arango, J. y Oliver, J. (eds.).La hora de la integración. Barcelona Anuario de la Inmigración en España,

Leal, J.y Sorando, D. (2016): "Economic Crisis, Social Change and Segregation Processes in Madrid," en Tammaru, T., M. van Ham, S. Marcińczak y S. Musterd (eds.).SocioEconomic Segregation in European Capital Cities. Londres: Routledge, pp. 214-237

Merton, R. K. et alt. (1963).Sociologia de la vivienda.Buenos Aires: Ediciones 3.

Módenes, J.A. y López Colas, J. (2014). "Cambio demográfico reciente y vivienda en España: ¿hacia un nuevo sistema residencial?" REIS №148 Pp. 103-134.

Naredo, J. M. (2010). "El modelo inmobiliario español y sus consecuencias". Boletín CF+S 44, 13-27.

Palacios García, A. (2008). "Fuentes estadísticas sobre la vivienda en España: un obstáculo para el diseño de la política de vivienda". Scripta Nova. Revista Electrónica de Geografía y Ciencias Sociales. Universidad de Barcelona. XII, (270): 38. (en línea) [http://www.ub.es/geocrit/sn/sn-270/sn-270-38.htm] [Consulta 15 de agosto de 2015].

Pareja Eastaway, M. y Sanchez Martínez, M.T. (2011). "El alquiler: una asignatura pendiente de la Política de Vivienda en España". Ciudad y Territorio. Estudios Territoriales XLIII (167).

Piketty, T. (2014). Capital in the Twenty-First Century. Cambridge, MA: Belknap.

Pittini, A., Koessl, G., Dijol, J., Lakatos, E. y Ghekiere, L. (2017). The State of Housing in the EU. Bruselas: Housing Europe.

Preteceille, E. (1971).La production des grands ensembles. Paris: CSU Centre de Sociologie Urbaine.

Rappoport, A. (1972). Vivienda y Cultura.Barcelona: Editorial Gustavo Gili, S.L.

Rex, J. y Moore, R. (1967).Race community and conflicto. Londres: Oxford University Press. 
Rodríguez, J. (2009). "Políticas de vivienda en un contexto de exceso de oferta". Madrid: Fundación Alternativas, documento de trabajo 155/2009, pp. 1-84.

Sánchez Martínez, M. T. (2002).La política de vivienda en España. Análisis de sus efectos redistributivos. Granada: Universidad de Granada, Biblioteca de Económicas y Empresariales.

Topalov, C. (1970).Les promoteurs immobiliers. Centre de Sociologie Urbaine. Paris.

Trabada, E. (2015). "De las ejecuciones hipotecarias al alquiler social". Documentación Social. No 176. Pp:95-152.

Tammaru, T., M. van Ham, Marcińczak, M. y Musterd, S. (eds.)(2017).Socio-Economic Segregation in European Capital Cities. Londres: Routledge, pp. 214-237.

Vinuesa, J. (2013).El festín de la vivienda: auge y caída del negocio inmobiliario en España. Madrid: Díaz y Pons. 